05

\title{
Асимметрия разрушения керамики при высокоскоростном ударе
}

\author{
(C) С.А. Зелепугин ${ }^{1,2}$, В.Ф. Толкачев ${ }^{1}$, А.С. Зелепугин ${ }^{1,2}$ \\ ${ }^{1}$ Национальный исследовательский Томский государственный \\ университет \\ ${ }^{2}$ Томский научный центр СО РАН \\ E-mail: szel@yandex.ru
}

Поступило в Редакцию 17 июля 2017 г.

Проведены экспериментальные исследования разрушения керамических преград при осесимметричном высокоскоростном ударе. Результаты исследований свидетельствуют о существенном влиянии структуры керамических материалов на процесс их разрушения, который становится асимметричным, что может приводить к вращению ударника при сохранении его первоначального направления движения. Моделей, описывающих асимметричный характер разрушения высокопрочной керамики, до сих пор не создано. Одним из возможных подходов для создания таких моделей может служить вероятностный подход к описанию прочностных характеристик материалов.

DOI: 10.21883/PJTF.2017.23.45275.16974

Высокопрочные керамические материалы и их комбинации с металлическими и композиционными материалами являются одними из наиболее перспективных элементов конструкций, предназначенных для эксплуатации в экстремальных условиях (в частности, при высокоскоростном ударе). Последние несколько десятилетий активно ведутся комплексные экспериментально-теоретические исследования по созданию физико-математических моделей деформирования и разрушения керамических материалов в условиях интенсивного ударно-волнового нагружения (плоского, осесимметричного, трехмерного) [1-5]. Наиболее актуален для изучения случай осесимметричного удара по керамическим преградам и преградам, содержащим керамические вставки, поскольку он наиболее разрушителен по своим итоговым последствиям (по сравнению с внедрением ударника под углом). Осесимметричный удар при изучении противоударной стойкости любых конструкций явля- 
ется оценкой сверху. Однако в подавляющем большинстве случаев при разработке моделей деформирования и разрушения керамических материалов при высокоскоростном ударе предполагается (явно или неявно), что если начальные условия взаимодействия характеризуются наличием симметрии, то и в процессе взаимодействия этот тип симметрии сохраняется [3,5,6-9]. Результаты исследований, представленные далее, доказывают, что для керамических материалов это предположение не всегда справедливо.

В настоящей работе проведены экспериментальные исследования разрушения керамических и керамикосодержащих преград на баллистическом стенде НИИ прикладной математики и механики Национального исследовательского Томского государственного университета. Были выбраны следующие условия проведения экспериментов. На баллистической трассе использовался штатный карабин СКС, патрон Б $7.62 \times 39$ (пуля со стальным сердечником с оживальной головной частью), расстояние до мишени $\sim 0.5 \mathrm{~m}$, скорость пули $760 \pm 3 \mathrm{~m} / \mathrm{s}$. В экспериментах особое внимание уделялось соблюдению условия осесимметричности соударения пули с преградой. В опытах проводилось рентгенографирование процесса, оценивались скорость деформированного сердечника пули в запреградном пространстве и характер разрушения преград. В качестве исследуемых преград были взяты керамическая преграда из карбида бора $\mathrm{B}_{4} \mathrm{C}$, керамический композит на основе $\mathrm{TiB}_{2}-\mathrm{B}_{4} \mathrm{C}$, трехслойная преграда, состоящая из лицевой и тыльной пластин из титанового сплава ВТ4 и среднего слоя из керамики $\mathrm{B}_{4} \mathrm{C}$.

На рис. 1 приведена рентгенограмма пробития пластины из керамики $\mathrm{B}_{4} \mathrm{C}$ в момент времени $120 \mu$ s после начала взаимодействия. Толщина керамической пластины составляла $5.1 \mathrm{~mm}$. Головная часть сердечника пули в данном случае деформируется в виде гриба симметричной формы вследствие высокого предела упругости материала преграды. На рентгенограмме видно, что разрушение керамической преграды происходит в зоне контакта с деформируемой головной частью пули. Через $120 \mu$ s после начала взаимодействия за пулей движется поток осколков различных размеров, в то же время каркас керамической преграды к рассматриваемому моменту времени сохраняет целостность. Однако процесс разрушения керамической преграды продолжается, полное разрушение керамической пластины заканчивается примерно к 200-250 $\mu$ s. После опыта данный образец находится в полностью

4 Письма в ЖТФ, 2017, том 43, вып. 23 


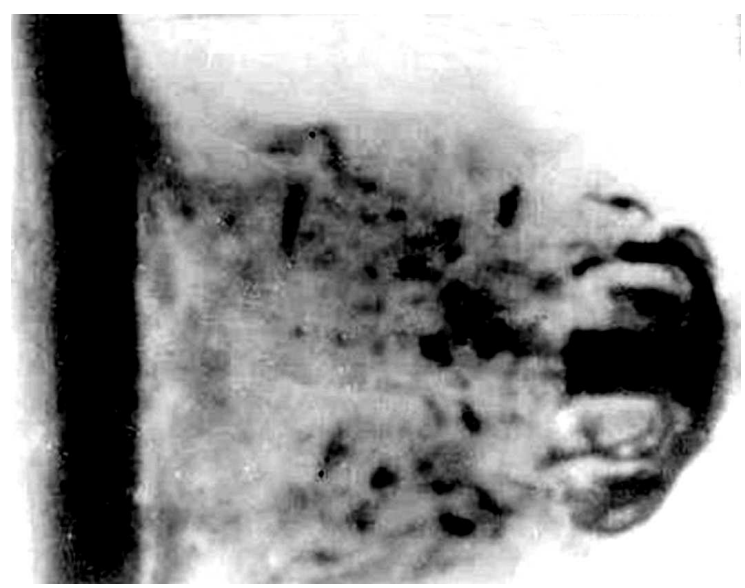

Рис. 1. Рентгенограмма пробития пластины из керамики $\mathrm{B}_{4} \mathrm{C}$ в момент времени $120 \mu \mathrm{s}$.

раздробленном состоянии, причем осколки имеют различные формы и размеры. Характерной особенностью процесса является сохранение осевой симметрии соударения, что проявляется в осесимметричной форме деформированной пули после взаимодействия с керамической преградой и в продолжении движения пули вдоль оси симметрии в запреградном пространстве.

На рис. 2 представлены рентгенограммы разрушения керамического композита на основе $\mathrm{TiB}_{2}-\mathrm{B}_{4} \mathrm{C}$ для моментов времени $50(a)$ и $200 \mu \mathrm{s}(b)$. Толщина композита составляла $6.4 \mathrm{~mm}$. Процесс разрушения композита во времени происходит следующим образом. На начальном этапе соударения деформируется головная часть сердечника пули, при этом форма пули имеет симметричный вид, что иллюстрируют рентгенограммы на рис. 2. После выхода ударной волны на тыльную поверхность преграды и отражения от нее в виде волны разгрузки в преграде начинается процесс накопления микроповреждений и формирования макроразрушений. Начинается процесс формирования откольного разрушения в тыльной области преграды. Материал керамического композита в области растягивающих нагрузок теряет прочностные характеристики и переходит в разрушенное

Письма в ЖТФ, 2017, том 43, вып. 23 


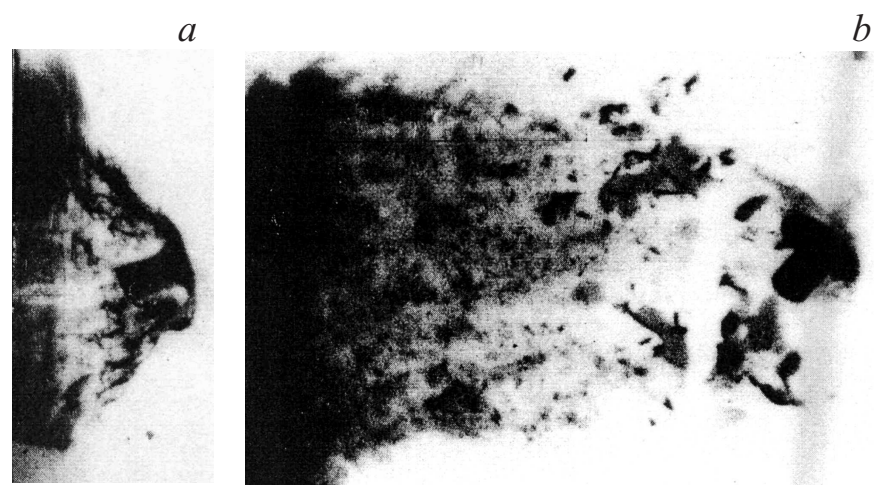

Рис. 2. Рентгенограмма пробития пластины из керамического композита на основе $\mathrm{TiB}_{2}-\mathrm{B}_{4} \mathrm{C}$ в моменты времени $50(a)$ и $200 \mu \mathrm{s}(b)$.

состояние. В первую очередь растягивающие нагрузки воздействует на область вдоль оси удара. В результате деформированный сердечник пули начинает внедряться в преграду, ослабленную волной разгрузки. К моменту времени $50 \mu \mathrm{s}$ от начала взаимодействия сердечник пули пробивает преграду, разрушает откольную „тарелочку“ и становится лидирующим элементом в запреградном потоке. Преграда к данному моменту времени еще сохраняет целостность вне зоны контакта. Процесс разрушения преграды продолжается, формируется поток осколков различных форм и размеров, что иллюстрирует момент времени $200 \mu \mathrm{s}$ на рис. 2. В конечном итоге преграда разрушается полностью.

Характерной особенностью данного процесса также является сохранение осевой симметрии соударения, что проявляется в продолжении движения пули вдоль оси симметрии в запреградном пространстве. Однако в отличие от предыдущего случая сердечник пули начинает вращаться в процессе пробития преграды, что объясняется асимметрией разрушения керамического композита. К моменту времени $50 \mu \mathrm{s}$ ось сердечника отклоняется против часовой стрелки в плоскости рисунка на $18^{\circ}$ от оси удара. К моменту времени $200 \mu$ s этот угол составляет $33^{\circ}$. Если предположить скорость вращения постоянной, то ее можно оценить как $0.1^{\circ} / \mu \mathrm{s}$.

4* Письма в ЖТФ, 2017, том 43, вып. 23 


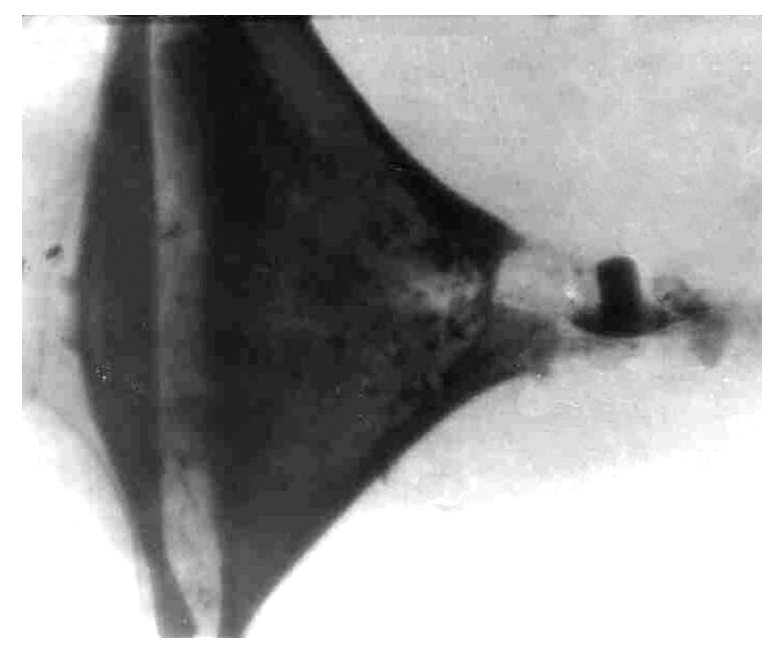

Рис. 3. Рентгенограмма пробития трехслойной преграды $\mathrm{Ti}-\mathrm{B}_{4} \mathrm{C}-\mathrm{Ti}$ в момент времени $180 \mu \mathrm{s}$.

На рис. 3 приведена рентгенограмма процесса пробития сердечником трехслойной конструкции, состоящей из пластины керамики карбида бора $\mathrm{B}_{4} \mathrm{C}$ толщиной $5.1 \mathrm{~mm}$ и лицевой и тыльной пластин из титанового сплава ВТ4 (обозначенного далее как Тi) толщиной $2 \mathrm{~mm}$ каждая, в момент времени $180 \mu \mathrm{s}$. На рентгенограмме отчетливо видно, что стальной сердечник пули деформируется в виде гриба симметричной формы, что свидетельствует о сохранении осевой симметрии процесса на начальной стадии взаимодействия пули с преградой. Пластины из титанового сплава деформируются в направлении векторов скоростей разлета осколков керамической преграды от лицевой и тыльной поверхностей, при этом тыльная пластина, очевидно, деформируется в значительно большей степени. Основную роль в деформировании тыльной титановой пластины играет воздействие сердечника пули, которое приводит к пробитию сердечником титановой пластины. Характерной особенностью данного процесса является сохранение направления движения деформированного сердечника пули и в то же время его поворот почти на $90^{\circ}$ вследствие асимметрии разрушения керамиче-

Письма в ЖТФ, 2017, том 43, вып. 23 
ской преграды. Титановые пластины замедляют процесс разрушения керамической преграды и разлет осколков, что усиливает воздействие на сердечник пули и приводит к более значительному повороту, чем в предыдущем случае.

Приведенные выше результаты экспериментальных исследований свидетельствуют о существенном влиянии структуры керамических материалов на процесс их разрушения, который становится асимметричным, что может приводить к вращению ударника при сохранении его первоначального направления движения. Упоминание об асимметричности разрушения встречается в научных работах (см., например, [10-12]). B [10] на основе экспериментальных данных описывается асимметричность откольного разрушения при высокоскоростном ударе. В [11] экспериментально и численно показана асимметрия взаимодействия пули с перфорированной преградой. В [12] приведены рентгенограммы процесса внедрения удлиненного стержня в керамическую преграду $\mathrm{SiC}$, иллюстрирующие несимметричность разрушения материала преграды. Моделей, описывающих асимметричный характер разрушения высокопрочной керамики, до сих пор не создано. Одним из возможных подходов для создания таких моделей может служить вероятностный подход к описанию прочностных характеристик материалов, развиваемый в $[13,14]$.

Работа выполнена при финансовой поддержке Российского научного фонда в рамках проекта № 16-19-10264.

\section{Список литературы}

[1] Румянцев Б.В. // Письма в ЖТФ. 2016. Т. 42. В. 17. С. 87-94.

[2] Румянцев Б.В. // ЖТФ. 2015. Т. 85. В. 4. С. 138-141.

[3] Holmquist T.J., Johnson G.R. // J. Appl. Phys. 2006. V. 100. P. 093525 (1-13).

[4] Kozachuk A.I., Kozhushko A.A., Rumyantsev B.V. et al. // Int. J. Impact Eng. 2003. V. 29. P. 385-390.

[5] Горельский В.А., Зелепугин С.А., Толкачев В.Ф. // Хим. физика. 1999. Т. 18. № 11. C. 104-107.

[6] Cao Y., Zhu S., Guo C. et al. // Appl. Comp. Mater. 2015. V. 22. N 4. P. 437-456.

[7] Савельева Н.В., Баяндин Ю.В., Савиных А.С. и др. // Письма в ЖТФ. 2015. T. 41. B. 12. C. 32-39.

[8] Branicio P.S., Kalia R.K., Nakano A. et al. // J. Mech. Phys. Solids. 2008. V. 56. N 5. P. $1955-1988$.

Письма в ЖТФ, 2017, том 43, вып. 23 
[9] Zelepugin S.A., Zelepugin A.S., Khristenko Yu.F. // ARPN J. Eng. Appl. Sci. 2016. V. 11. N 24. P. 14560-14565.

[10] Хорев И.Е. // Письма в ЖТФ. 2005. Т. 31. В. 4. С. 71-75.

[11] Kilic N., Bedir S., Erdik A. et al. // Mater. Design. 2014. V. 63. P. 427-438.

[12] Anderson C.E., Jr., Behner Th., Orphal D.L. et al. // Int. J. Impact Eng. 2008. V. 35. P. 661-673.

[13] Gerasimov A.V. // 11th World Congress on computational mechanics (WCCM2014), 5th Eur. Conf. on computational mechanics (ECCM-2014) and 6th Eur. Conf. on computational fluid dynamics (ECFD-2014). 2014. V. 4. P. 3934-3940.

[14] Герасимов А.В., Добрица Д.Б., Пашков С.В., Христенко Ю.Ф. // Космические исследования. 2016. Т. 54. № 2. С. 126-134. 